\title{
Pyomyositis and osteomyelitis: an unusual cause of abdominal pain
}

\author{
Michimasa Fujiwara, Yoshiko Abe, Aya Kodera, Tooru Araki
}

Department of Pediatrics, National Hospital Organization Fukuyama Medical Center, Fukuyama, Japan

\section{Correspondence to} Dr Michimasa Fujiwara, miclegend2020@yahoo.co.jp

Accepted 28 February 2018

\section{DESCRIPTION}

A previously healthy 12-year-old boy was referred with a 2-day history of fever and abdominal pain in the right lower quadrant. He had no traumatic episodes. A physical examination indicated tenderness of the right lower quadrant without rebound tenderness and muscular defence. His gait was normal. His white blood cell count was $4.6 \times 10^{9} / \mathrm{L}$ and his $\mathrm{C}$ reactive protein (CRP) value was $5.9 \mathrm{mg} /$ $\mathrm{dL}$. The findings of abdominal ultrasound examination and enhanced CT were normal and ruled out appendicitis. Mesenteric lymphadenitis was initially diagnosed and empirical therapy with intravenous cefmetazole $100 \mathrm{mg} / \mathrm{kg} /$ day was started. On day 3 after admission, his fever abated. However, his blood culture was positive for methicillin-susceptible Staphylococcus aureus (MSSA), and his abdominal pain persisted. Contrast-enhanced MRI revealed hyperintense signals on T2-weighted images in the right internal abdominal oblique muscles (figure 1A) and in the right proximal femur (figure 1B). Inflammation did not involve the skin surface, right external oblique muscle, hip joint or pelvic muscles. We ultimately diagnosed pyomyositis of the right internal abdominal oblique muscle and osteomyelitis of the proximal femur due to MSSA bacteraemia. Cefmetazole was switched to cefazolin $150 \mathrm{mg} / \mathrm{kg} /$ day for 2 weeks, which caused his blood culture to become negative. Antibiotic therapy was switched to oral cefaclor $50 \mathrm{mg} / \mathrm{kg} /$ day after erythrocyte sedimentation rates and CRP values had normalised. He continued with cefaclor for 4 weeks and completed a total of 6 weeks of systemic antibiotic therapy. Drainage was unnecessary because of a favourable response to the antibiotics. He remained asymptomatic at 1 year of follow-up.

We described a patient with rare pyomyositis and osteomyelitis that were caused by MSSA infection in an immunocompetent boy. Pyomyositis is a primary

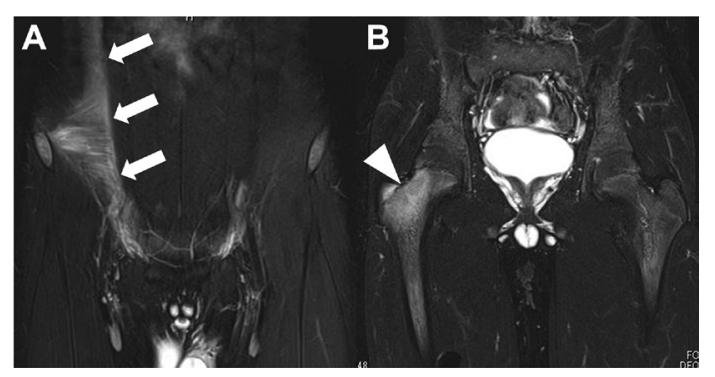

To cite: Fujiwara $M$, Abe $Y$ Kodera $\mathrm{A}$, et al. BMJ Case Rep Published Online First: [please include Day Month Year]. doi:10.1136/bcr-2017223871
Figure 1 Fat-saturated T2-weighted coronal imaging showing hyperintense signal both in the right internal abdominal oblique muscle ( $\mathrm{A}$, arrows) and in the right proximal femur ( $B$, arrowhead). pyogenic infection of the skeletal muscle. Patients with pyomyositis usually present with fever, acute muscle pain and a limp because the predilection sites of pyomyositis are the lower limbs and pelvic muscle. ${ }^{1}$ The abdominal wall including the internal abdominal oblique muscle accounts for only 1.6\% of all sites of pyomyositis. ${ }^{1}$ Another review revealed that all of 45 patients with pyomyositis were affected by position except abdominal wall. ${ }^{2}$ Therefore, the presentation of pyomyositis as abdominal pain in the present case was unusual.

Enhanced CT was not informative in this patient, whereas MRI led to a definitive diagnosis. MRI is the most useful diagnostic modality because it can identify coexisting bone involvement. ${ }^{3}$ Delayed diagnosis and treatment of pyomyositis contribute to various complications such as osteomyelitis and septic arthritis, with osteomyelitis being the most frequent $(41 \%){ }^{2}$ The fever and right quadrant pain in this patient might have resulted from pyomyositis of the abdominal wall, whereas he had no thigh pain or gait disturbance that suggested femoral osteomyelitis. Therefore, the osteomyelitis in this patient was considered secondary to the bloodstream infection caused by MSSA.

Pyomyositis is difficult to diagnose due to extremely diverse clinical manifestations. In conclusion, all clinicians should have a high degree of suspicion and an understanding of pyomyositis to ensure early diagnosis and treatment that will prevent severe complications and sequelae.

\section{Learning points}

Patients with non-specific abdominal pain should be considered for pyomyositis of abdominal wall.

- MRI is the most useful modality to diagnose pyomyositis.

Contributors MF, YA, AK and TA treated the patient. MF drafted the manuscript. TA reviewed and revised the manuscript, and all authors approved the final manuscript.

Funding The authors have not declared a specific grant for this research from any funding agency in the public, commercial or not-for-profit sectors.

Competing interests None declared.

Patient consent Parental/guardian consent obtained.

Provenance and peer review Not commissioned; externally peer reviewed.

(c) BMJ Publishing Group Ltd (unless otherwise stated in the text of the article) 2018. All rights reserved. No commercial use is permitted unless otherwise expressly granted. 


\section{REFERENCES}

1 Bickels J, Ben-Sira L, Kessler A, et al. Primary pyomyositis. J Bone Joint Surg Am 2002;84-A:2277-86.
2 Pannaraj PS, Hulten KG, Gonzalez BE, et al. Infective pyomyositis and myositis in children in the era of community-acquired, methicillin-resistant Staphylococcus aureus infection. Clin Infect Dis 2006;43:953-60.

3 Gubbay AJ, Isaacs D. Pyomyositis in children. Pediatr Infect Dis J 2000;19:1009-12.

Copyright 2018 BMJ Publishing Group. All rights reserved. For permission to reuse any of this content visit http://group.bmj.com/group/rights-licensing/permissions.

BMJ Case Report Fellows may re-use this article for personal use and teaching without any further permission.

Become a Fellow of BMJ Case Reports today and you can:

- Submit as many cases as you like

- Enjoy fast sympathetic peer review and rapid publication of accepted articles

- Access all the published articles

- Re-use any of the published material for personal use and teaching without further permission

For information on Institutional Fellowships contact consortiasales@bmjgroup.com

Visit casereports.bmj.com for more articles like this and to become a Fellow 